\title{
LEVEDURAS NA CAVIDADE BUCAL DE INDIVÍDUOS IRRADIADOS PELO CÉSIO 137 EM GOIÂNIA-GO*
}

\author{
Maria do Rosário Rodrigues Silva " , Carla Camargo Wascheck“*, \\ Maria Aparecida Monteiro "*, Orionalda de Fátima Lisboa Fernandes"., \\ Hildene Menezes Silva ${ }^{\cdots \cdot}$, Marcia Abrão ${ }^{\cdots}$
}

\section{RESUMO}

Em 50 amostras de pacientes irradiados pelo Césio 137, durante o acidente radioativo ocorrido em Goiânia-Go, em 1987, verificou-se a presença de leveduras na mucosa oral de 54\% destes indivíduos 4 anos após o acidente. A coloraçāo pelo Gram e o cultivo em ágar Sabouraud à temperatura ambiente foram usadas para diagnóstico. Produçāo de clamidoconídios em meio de ágar corn meal + tween 80 , formaçāo de tubo germinativo em soro animal, provas de assimilaçāo e fermentaçāo de carbohidratos permitiram a identificaçāo das leveduras. $\mathrm{O}$ teste de $\mathrm{X}^{2}$ mostrou que a presença de Candida albicans na boca de indivíduos irradiados nāo foi estatisticamente significante a $5 \%$ quando comparados com indivíduos nāo irradiados que serviram como controle.

Unitermos: Candidíase, Radiação, Césio 137.

\section{INTRODUÇĀO}

Em setembro de 1987, um antigo equipamento de radioterapia que se encontrava abandonado nas instalaçôes do Instituto Goiano de Radioterapia na cidade de Goiânia foi retirado indevidamente por dois indivíduos desempregados. A fonte

\footnotetext{
- Trabalho desenvolvido Dept. ${ }^{\circ}$ de Microbiologia - IPTSP/UFG

- Professora do Depto. de Microbiologia do IPTSP/UFG

-.. Odontólogas da Fundaçāo Leide das Neves

*.. Biomédica do Depto. de Microbiologia

- Recebido para publicação em 05/07/94
} 
SILVA,M.R.R.; WASCHECK,C.C.; MONTEIRO,M.A.; FERNANDES,O.F.L.; SILVA,H.M.; ABRĀO,M. Leveduras na cavidade bucal de indivíduos irradiados pelo Césio $137 \mathrm{em}$ Goiânia-Go. Rev.Pat. Trop.,23(1):113-119,jan./jun.,1994.

de energia desse equipamento, o Césio 137, depois de quebrada, foi distribuída a amigos e parentes que a manusearam ou estiveram próximos a ela por vários dias, havendo até ingestão do material radioativo por alguns deles. Cerca de 244 pessoas foram encaminhadas para cuidados médicos especiais. 50 indivíduos altamente contaminados, ou seja, que apresentaram radiometria e ou dosimetria do corpo inteiro maior ou igual a 20 rads, constituíram o alvo do nosso trabalho. $9(18 \%)$ destes indivíduos apresentaram lesões produzidas por Candida na cavidade bucal observadas durante o período de irradiação, as quais, estavam sempre associadas com número reduzido de leucócitos e de plaquetas contados no sangue periférico e com indivíduos que haviam recebido alta radiação (> 1,3 Gy) (2).

Fungos, bactérias, vírus e protozoários podem viver na cavidade bucal como saprófitas, mas em condiçōes especia is o relacionamento destes microrganismos com o hospedeiro pode ser alterado predispondo-o a infecções $(5,9,11)$.

Radiações ionizantes podem alterar a susceptibilidade de indivíduos a infecções, portanto fungos presentes na mucosa oral como saprófitas poderiam passar a patógenos.

No presente trabalho, será verificado a ocorrência de leveduras na cavidade bucal de indivíduos, que em 1987 foram altamente contaminados e ou irradiados pelo Césio 137.

\section{MATERIAL E MÉTODOS}

Entre julho de 1991 e julho de 1992 foi coletado material da boca de 50 indivíduos, sendo 25 do sexo feminino e 25 do sexo masculino, com idades variando de 3 a 67 anos $(x=27,22$ e s=16,18) irradiados com Césio 137 em setembro de 1987 e que estão sendo, com regularidade, acompanhados clinicamente pelos profissionais da área de saúde da Fundação Leide das Neves. Estas pessoas sofreram irradiação e ou contaminação pelo Cs 137 durante período estimado de 15 dias em doses fracionadas. $\mathrm{O}$ cálculo de dose recebida foi feita pela dosimetria citogenética bascado na curva de cobalto 60 estimada para o Cs 137.

Nesta mesma época, foi também coletado material da boca de 50 indivíduos não irradiados, sendo 25 do sexo feminino e 25 do sexo masculino com
SILVA,M.R.R.; WASCHECK,C.C.; MONTEIRO,M.A.; FERNANDES,O.F.L.; SILVA,H.M.; ABRĀO.M Leveduras na cavidade bucal de indivíduos irradiados pelo Césio $137 \mathrm{em}$ Goiânia-Go. Rev.Pat. Trop.,23(1):113-119,jan./jun.,1994.

idades variando de 6 a 72 anos $(x=26,86$ e $s=15,84)$ que se submetiam a tratamento odontológico na Faculdade de Odontologia da Universidade Federal de Goiás e que foram utilizados como controle, levando-se em consideração ainda o uso de próteses dentárias e fumo, similares aos dos pacientes irradiados.

A coleta dos grupos estudados (irradiados e controles) foi dividida em duas etapas. A primeira ocorreu no início do tratamento específico para dentística restauradora e técnicas de higiene e a segunda após o seu término. O material da língua, palato e mucosa jugal foi retirado com swabs esterilizados e colocados em solução salina a $0,85 \%$. Nenhum dos indivíduos apresentou lesōes visíveis, macroscopicamente, na mucosa oral.

Todo material foi submetido a exame direto corado pelo Gram e cultivado em ágar Sabouraud dextrose mantido à temperatura ambiente.

As colônias com aspecto úmido, cremoso e de cor branca amareladas características das leveduras, foram identificadas segundo Kreger-Van Rij (7) c Lodder (8), através de:

1 - Fenômeno de Reynolds Braude, que consiste na Incubação a $37^{\circ} \mathrm{C}$. em soro animal por 2 a 3 horas para verificar a produção de tubo germinativo.

2 - Inoculação em ágar corn meal acrescido de tween 80 para observar a formação de clamidoconídios.

3 - Provas de assimilação e fermentação de hidratos de carbono, utilizadas para identificar as várias espécies de Candida.

$\mathrm{O}$ teste de qui-quadrado $\left(\mathrm{X}^{2}\right)$ foi usado para verificar se havia diferença significativa entre a presença de Candida albicans isoladas na boca de indivíduos irradiados e controles.

\section{RESULTADOS}

Dos indivíduos irradiados, o exame direto corado pelo Gram mostrou leveduras em 27 casos (54\%). Este número foi o mesmo nas duas coletas. Em 6 amostras $(21,5 \%)$ verificou-se além de leveduras a formação de pseudomicélio. Nos indivíduos controles, não irradiados, observou-se 15 amostras com leveduras ao exame direto corado pelo Gram nas duas coletas. Para todos os casos verificou-se que a positividade para levedura, ocorria nos mesmos indivíduos antes e após o tratamento de dentística restauradora. A higiene e o tratamento dentário não influenciaram nos resultados obtidos. 
SILVA,M.R.R.; WASCHECK,C.C.; MONTEIRO,M.A.; FERNANDES,O.F.L.; SILVA,H.M.; ABRÄO,M Trop.,23(1):113-119,jan./jun.,1994.

As amostras positivas ao exame direto foram devidamente identificadas e seus resultados figuram na tabela 1 .

Tabela 01 - Identificação de leveduras coletadas no início e no término do tratamento odontológico da boca de indivíduos irradiados com o Cs 137 e de não irradiados.

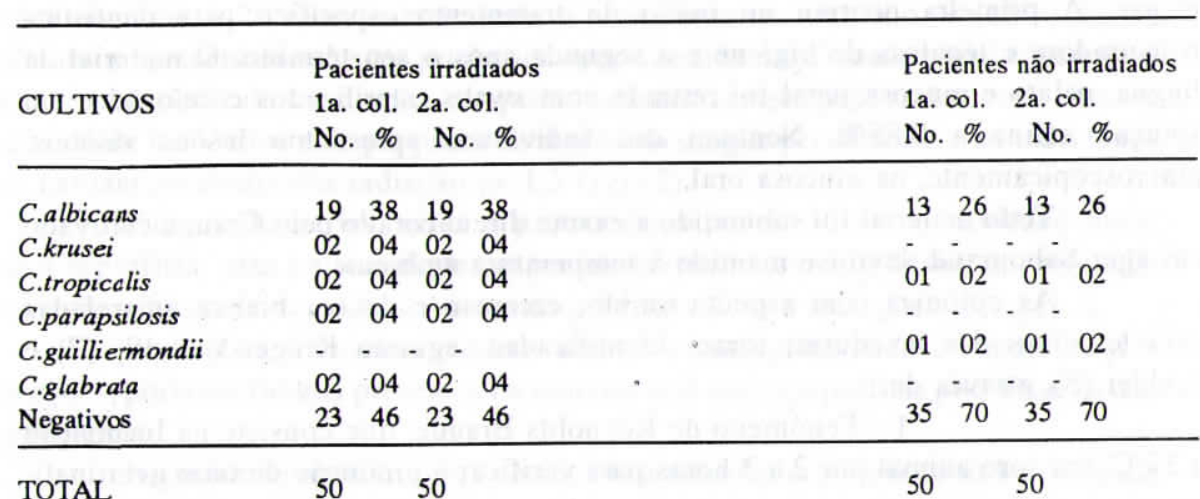

TOTAL

$50 \quad 50$

Nos indivíduos irradiados verificou-se que a colonização por leveduras ocorria numa proporçāo de 1,25:1,00 de feminino para masculino e nos não irradiados eșta proporção era de 1,50:1,00, também maior para o sexo feminino; com a idade variando de 10 a 60 anos em ambas as amostragens.

A análise estatística pelo teste de $\mathrm{X}^{2}$ de Mantel-Haenszel com relação a presença de Candida albicans na mucosa oral de indivíduos irradiados, mostrou que ao nível de significância de $5 \%$ não havia associação entre a presença desta levedura e irradiação pelo Césio 137 , havendo um forte indício de que a irradiação nāo favoreceu a formação de colônias de Candida albicans na mucosa oral dos indivíduos estudados.

\section{DISCUSSĀO}

As várias conseqüências decorrentes do acidente com o Césio 137, entre elas a presença de lesões orofaciais significantes em 12 pacientes, onde se observou candidase oral em 5, motivou este trabalho. Um ano após o acidente, GALE e cols.(1 verificaram que algumas vítimas continuavam a excretar elementos
SILVA,M.R.R.; WASCHECK,C.C.; MONTEIRO,M.A.; FERNANDES,O.F.L.; SILVA.H.M.; ABRĀO.M. Leveduras a cavidade bucal de indivíduos irradiados pelo Césio $137 \mathrm{em}$ Goiânia-Go. Rev.Pat. Trop..23(1):113-119,jan./jun.,1994.

radioativos na urina. Passados mais de 4 anos do acidente, apesar da ausência de lesōes de mucosa oral nos indivíduos em estudo, verificou-se um porcentual bem elevado de leveduras $(54 \%)$ presentes nesta mucosa.

Candida albicans predominou na colonização da orofaringe em nosso estudo, e segundo ODDS (10) isto ocorre devido às propriedades específicas de aderência demostrada por esta levedura. TODD e cols.(12), já em 1937 verificaram que Candida albicans está presente na mucosa oral de 30 a $50 \%$ de indivíduos normais. Esta levedura foi isolada em $38 \%$ das amostras coletadas de indivíduos irradiados contra $26 \%$ dos não irradiados, verificando-se que não havia diferença estatisticamente significativa entre as duas amostras. Por este resultado, não se pode estabelecer, após 4 anos relação entre presença de Candida albicans na mucosa oral c indivíduos irradiados pelo Césio 137 em 1987.

Com relação ao sexo, idade e higienização da mucosa oral após o tratamento de dentística restauradora, estes elementos nāo pareceram influir na colonização de leveduras na mucosa oral. De acordo com HOLBROOK e cols.(4) as infecções por Candida na mucosa oral são mais comuns no sexo feminino devido ao uso de próteses dentárias. HUBEN e cols.(6) observaram que cuidados padrōes de higiene em serviços de terapia intensiva não afetavam a proporção de colonização por Candida albicans.

Outras leveduras também foram encontradas colonizando a mucosa oral dos indivíduos estudados. Há vários relatos de outras leveduras como Candida krusei e Torulopsis glabrata isoladas de mucosa oral de indivíduos imunodeprimidos, causando lesôes $(3,13)$.

\section{SUMMARY}

Yeasts from the oral cavity in patients irradiated by caesium 137 in Goiânia-

In 50 samples collected from patients who were irradiated by caesium 173, during the radiative accident held in Goiânia-Go, in 1987, the presence of yeasts observed in the oral mucous membrane of $54 \%$ of these individuals after 4 years ago.

It has been used to diagnose, the stain by Gram and cultive in sabouraud ágar. Production of clamydoconidias in corn meal+tween 80 , formation 
SILVA,M.R.R.; WASCHECK,C.C.; MONTEIRO,M.A.; FERNANDES,O.F.L.; SILVA,H.M.; ABRĀO,M Leveduras na cavidade bucal de indivíduos irradiados pelo Césio 137 em Goiânia-Go. Rev.Pat. Trop.,23(1):113-119,jan.jjun.,1994.

of germinative tube in animal serum and proofs of assimilation and fermentation of carbohydrates permitted the identification of Candida species.

The number of Candida albicans presented in the irradiated individual mouth don't show statistically significant to $5 \%$, in comparison to the non irradiated individuals who were used as control.

KEYWORDS: Candidiasis, Radiation, Caesium 137

\section{REFERÊNCIAS BIBLIOGRÁFICAS}

01. GALE,R.P.; THOMPSON,M.A \& CRAWFORD,M.A Recent radiation accidents Chernobyl and Goiânia: Their impact and global implications. Ala J.Med.Sci.,25: 439-44,1988

02. GOMES,M.A.; WASCHECK,C.C.; SCULLY,C.; ALMEIDA,P.A. \& BOZO,L. Orofacial manifestations from accidental exposure to caesium 137 in Goiânia, Brasil. J.Oral Pathol.Med., 19:322-5,1990

03. GILQUIM,J.; LAVARDE,V.; MEGGLE,F. \& ACAR,J.F. Selection of fluconazole-resistant yeasts in AIDS patients under fluconazole prophylaxis. VI International Conference on AIDS. San Francisco, June,1990 (Abstract 2112)

04.HOLBROOK,W.P. \& RODGERS,G.D. Candidal infection experience in o British dental hospital. Oral Medicine, 49(2):122-5,1980

05. HILL,L.V.H.; TAN.M.H.; PEREIRA,L.H. \& EMBIL,J.A. Association of oral candidiasis with diabetic. J.Clinical Pathol.,42:502-5,1989
SILVA,M.R.R.; WASCHECK,C.C.; MONTEIRO,M.A.; FERNANDES,O.F.L.; SILVA.H.M.; ABRĀO,M. Leveduras na cavidade bucal de indivíduos irradiados pelo Césio 137 em Goiânia-Go. Rev.Pat.. Trop.,23(1):113-119,jan.jjun.,1994.

06. HUBEN,H. \& HAUCK,H. Characterization of Candida albicans strains foud in patients of three intensive care units. Mycoses,31(8):418-22,1987

07. KREGER-VAN RIJ,N.J.W. The yeasts: taxonomic study. 3 ed., Amsterdan, Elseveier,1984

08. LODDER,J. The yeasts: a taxonomic study. 2 ed., Amsterdan, Elseveier, North Holland,1970

09. MENDONZA,A.G. Opportunistic mycoses. The International Symposium on Mycoses PAHO 205:39-45,1970

10. ODDS,F. Candida and candidoses. A review and bibliography. 2 ed. London, Philadelphia. Bailliere Tindall,1988

11. POPE,L.M.; COLE,G.T.; GUENTZEL,M.N \& BERRY,L.J. Systemic and gastrointestinal of infant mice after intragastric challenge. Infection and immunity 25: 702-7,1979

12. TODD,R.L. Studies on yeasts-like organism isolated from the mouth and throats of normal persons. Amer.J of Higiene 25:212,1937

13. WINGARD,J.R.; MERZ,W.G.; RINALDI,M.G.; JONHSON,T.R.; KARP,J.E. \& SARAI,R. Increase in Candida kruseii among patients with bone-marrow transplantation and neutropenia treated prophylactically with fluconazole. N.Engl.J.Med.,325:1274-7,1991 